\title{
História da ciência: revelando concepções fragmentadas a partir de imagens de cientistas
}

\author{
History of science: revealing fragmented conceptions from scientists \\ 'images
}

\author{
Eduarda Tais Breunig ${ }^{1}$ \\ Aléxia Santos Amaral ${ }^{2}$ \\ Andréa Inês Goldschmidt ${ }^{3}$
}

\section{Resumo}

A pesquisa buscou investigar as concepções de alunos de terceiro ano do ensino médio a respeito da imagem e do nome de três cientistas importantes para a Biologia: Robert Hooke, Anton Van Leeuwenhoek e Carl Nilsson Linnaeus (Carlos Lineu), através de questionários aplicados a setenta e oito alunos dos terceiros anos do ensino médio, de três escolas públicas do município Palmeira das Missões, RS. Inicialmente foi aplicado o primeiro instrumento de investigação, contendo duas imagens distintas de cada um dos cientistas e com questões semiestruturadas (fechadas e abertas). Em um segundo momento, foi aplicado um segundo questionário, que além de outras imagens dos cientistas, apresentavam os nomes dos mesmos. Após, os questionários foram recolhidos e tabulados. Os resultados mostram que o uso de imagens ainda é restrito em sala de aula; não tendo sido reconhecidos nenhum dos cientistas. Além disso, muitas concepções errôneas sobre cientistas e a ciência foram identificadas nas citações dos alunos. Apresentar de forma adequada e ampliada a História da Ciência pode contribuir como um dispositivo didático útil, tornando o ensino da ciência a nível médio mais interessante, além de facilitar a aprendizagem, mostrando que a ciência não é imutável e que depende de diversas pessoas.

Palavras-chaves: Hooke; Leeuwenhoek; Lineu.

\section{Abstract}

The research aimed to investigate the conceptions of third year high school students regarding the image and name of three important scientists for Biology: Robert Hooke, Anton Van Leeuwenhoek and Carl Nilsson Linnaeus (Carlos Lineu), through questionnaires applied to seventy-eight students of third-year high school from three public schools in the municipality of Palmeira das Missões, RS. Initially the first research instrument was applied, containing two distinct images of each scientist and with semistructured questions (closed and open). Then, a second questionnaire was applied in which, besides having other images of the scientists, presented the names of the scientists mentioned. After that, the questionnaires were collected and tabulated. The results show that the use of images is still restricted in the classroom; and none of the scientists were recognized. In addition, many misconceptions about scientists and science have been identified in the students' citations. Presenting adequately and broadly the History of Science may contribute to a useful didactic device, making the

\footnotetext{
${ }^{1}$ Universidade Federal de Santa Maria | dudabreunig@hotmail.com

${ }^{2}$ Universidade Federal de Santa Maria | alexiaamaral79@hotmail.com

${ }^{3}$ Universidade Federal de Santa Maria | andreainesgold@gmail.com
} 
teaching of science become more interesting for the high school level. Also, it may ease the learning, showing that science is not immutable and it depends on several people.

Keywords: Hooke; Leeuwenhoek; Lineu.

\section{Introdução}

Nos últimos anos, as pesquisas em ensino de ciências têm evidenciado a relevância do papel desempenhado pela inserção da História e Filosofia da Ciência (HFC) no ensino e aprendizagem das ciências.

Segundo Martins (2007) a HFC apresenta múltiplas dimensões. Por um lado, representa um amplo campo de estudos e pesquisas, como bases teóricas e especificidades. E, por outro lado, constitui-se uma área do conhecimento com fortes e profundas implicações para a didática das ciências. Sobre essa segunda dimensão versará o foco desse trabalho, sendo relatada um pouco da História da Ciência $(\mathrm{HC})$ baseada em três importantes renomes da ciência, que contribuíram muito para os avanços das ciências/biologia. São eles: (1) Robert Hooke, (2) Anton Van Leeuwenhoek e (3) Carl Nilsson Linnaeus (Carlos Lineu). Conhecer sobre a HC, tem grande importância, e de acordo com Mathews (1995), a HFC é apresentada como uma alternativa para a constante desmotivação com o Ensino de Ciências que tem culminado em altos índices de analfabetismo científico e de evasão escolar.

De uma maneira geral, entre os argumentos para a utilização da HFC são apontados que: humaniza o conteúdo ensinado; favorece uma melhor compreensão dos conceitos científicos, pois os contextualiza e discute seus aspectos obscuros; ressalta o valor cultural da ciência; enfatiza o caráter mutável do conhecimento científico; e, permite uma melhor compreensão do método científico (MATTHEWS, 1995; HÖTTECKE e SILVA, 2011).

Martins (1998) sinaliza que por meio de uma abordagem sobre a HC, o professor deve mostrar através de episódios históricos o processo gradativo e lento de construção do conhecimento, permitindo uma visão mais concreta da natureza real da ciência, seus métodos, suas limitações, o que levará a formação de um espírito crítico fazendo com que o conhecimento científico seja desmitificado sem, entretanto, ser destituído de valor.

Melzer e Aires (2015) discutem que o desejável é que a abordagem HFC possibilite a compreensão de como os fatos narrados foram produzidos, quais indivíduos estiveram envolvidos nessa produção e como esses fatos estão interligados com os aspectos sociais, políticos e econômicos de determinada época.

Cachapuz et al. (2011) discutem sobre a necessidade do professor em intervir, atuando como um mediador dessas fragmentadas informações e sinalizam para a importância em aprofundar esses aspectos na formação epistemológica dos professores, bem como aspectos relativos à concepção de aprendizagem; pois, segundo os autores, o modo como se ensina as Ciências tem a ver com o modo como se concebe a Ciência que se ensina, e o modo como se pensa que o outro aprende o que se ensina (bem mais do que o domínio de métodos e técnicas de ensino).

Várias pesquisas têm demonstrado concepções deformadas de ciências e de cientista, amplamente difundidas pelos meios de comunicação, e que limitam as atividades científicas somente à experimentação e às grandes contribuições (ZANON e MACHADO, 2013). Essa imagem da ciência e dos cientistas é totalmente fragmentada e ainda, estereotipada, no caso dos cientistas, pois a ciência perpassa tais conclusões, e, todavia, os meios de 
comunicação exercem forte influência sobre essas concepções. Com isso, é importante desenvolver com os alunos a ideia de que a ciência foi e é construída por cientistas que se dedicaram muito, cometeram diversas tentativas frustradas até chegar a um resultado final. Além disso, é de extrema importância ressaltar em sala de aula, que existem diversas pessoas envolvidas em todo o processo de construção do conhecimento; ou seja, não foi apenas um cientista que contribuiu para tais "verdades" que conhecemos hoje, e, não obstante, que essas contribuições, denominadas erroneamente como verdades, não devem ser tratadas como "imutáveis", pois isso faz com que não se construa justamente o olhar reflexivo e crítico sobre a ciência.

Esse artigo buscou investigar o conhecimento de alunos concluintes do ensino médio, a respeito de alguns cientistas e suas contribuições para a ciência. Após a pesquisa, foi realizada uma apresentação sobre cada cientista, relatando sua vida e obra, de modo, sempre realista, buscando elucidar aos alunos por meio da história da ciência como realmente tais conhecimentos foram construídos.

\section{Trajetória metodológica}

Com o intuito de proporcionar aos alunos dos terceiros anos do ensino médio uma oportunidade de vivenciar momentos de aprendizagem a respeito da $\mathrm{HC}$ envolvendo três brilhantes cientistas, foi realizada uma entrevista semiestruturada, seguida de uma apresentação sobre os pesquisadores: Robert Hooke, Anton Van Leeuwenhoek e Carl Nilsson Linnaeus (Carlos Lineu), a que se referiam os instrumentos de investigação. Os cientistas escolhidos são nomes que aparecem em livros de Biologia do Ensino Médio.

A pesquisa foi desenvolvida pelo grupo de pesquisadores, autores deste artigo e que se encontram em formação inicial docente em Ciências Biológicas, com discentes de três turmas do terceiro ano do Ensino Médio, totalizando 78 participantes, em três escolas públicas do município de Palmeira das Missões, RS.

Os alunos foram convidados a participarem da pesquisa, assinando um termo livre e esclarecido.

Para avaliar o conhecimento prévio dos entrevistados, a pesquisa foi desenvolvida em dois momentos, dos quais os alunos desconheciam. Inicialmente foi aplicado um questionário, contendo distintas imagens dos cientistas, sem seus nomes e com questões semiestruturadas (fechadas e abertas). Nesse, foram questionados sobre quem se referia à imagem, se tratava ou não de um cientista e quais as justificativas para tal resposta. Em um segundo momento, foi aplicado outro questionário, que além de conter outras imagens dos mesmos cientistas selecionados, apresentava os nomes dos mesmos. Nesse foram questionados, se os discentes conheciam o cientista pela imagem e/ou pelo nome e se conheciam suas contribuições para a ciência. Após isso, os questionários foram recolhidos e tabulados, sendo apresentados e discutidos os resultados encontrados.

Em sala de aula, após a investigação realizada, foi feita uma apresentação sobre os três cientistas que estavam presentes nos questionários, onde se relatou um pouco da vida e obra, dando ênfase a aspectos que muitas vezes são ocultados pelos livros didáticos ou então pela mídia. 


\section{Resultados e discussões}

Tabela 1. Resultados percentuais encontrados para as imagens do cientista Robert Hooke, sem a identificação pelo nome, entre alunos concluintes do ensino médio em escolas públicas do interior do estado do Rio Grande do Sul.

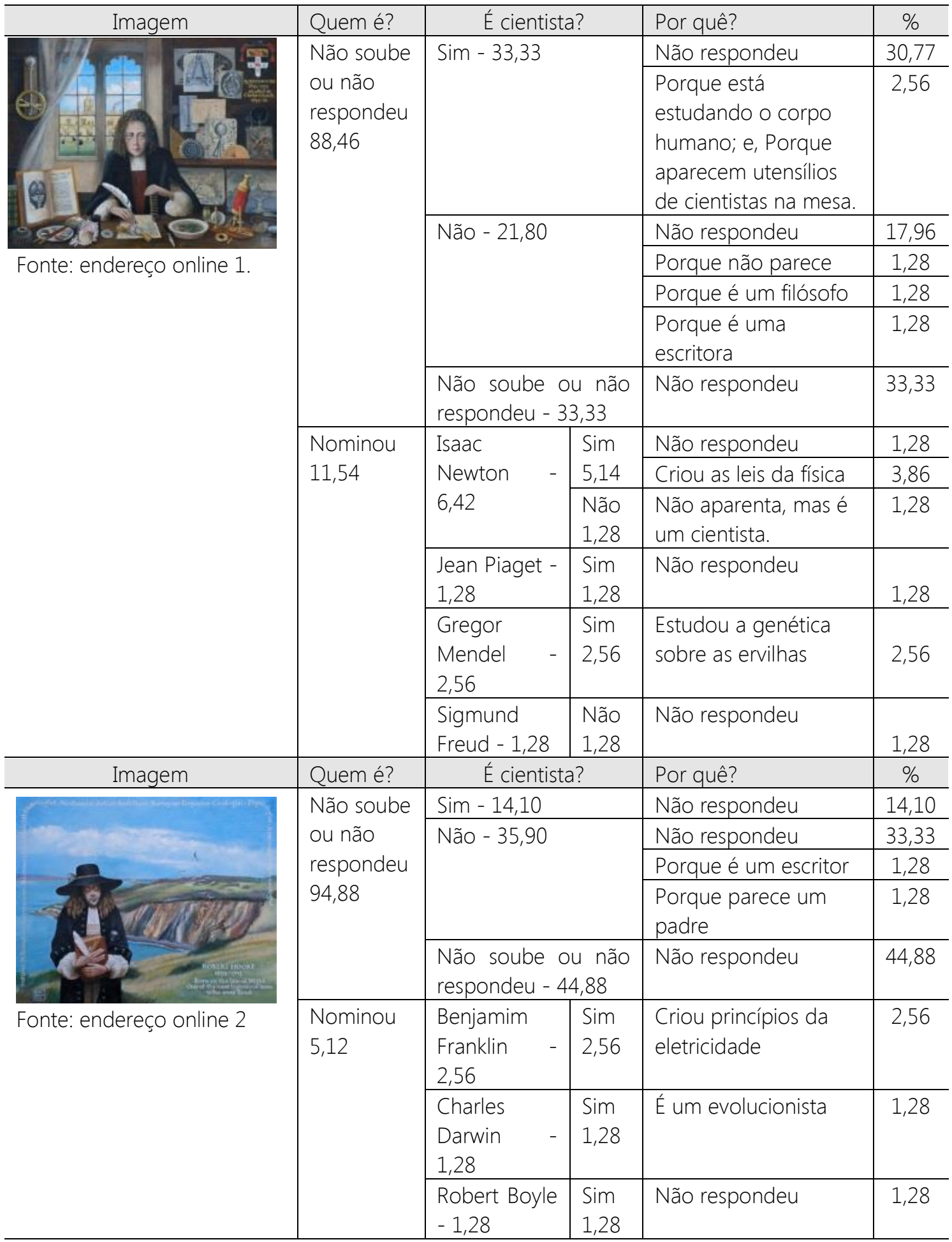

Ao analisar os resultados referentes à primeira parte do questionário, em que foram apresentadas apenas as imagens dos cientistas, sem a identificação, verificou-se que os três 
cientistas selecionados para a pesquisa, não foram reconhecidos pelos alunos. Já, no segundo questionário, em que eram apresentadas as imagens seguidas dos nomes dos pesquisadores, os resultados mostraram que os alunos praticamente não os identificaram, elucidando que a abordagem histórica quase não se faz presente no ensino de ciências.

A Tabela 1 apresenta os percentuais analisados para o primeiro questionário, contendo imagens sem o nome do cientista Robert Hooke.

Ao comparar os resultados da primeira imagem com os resultados da segunda imagem do cientista Robert Hooke, verificou-se que os participantes tiveram maior facilidade em responder as questões levando em consideração os elementos contidos na primeira imagem. Embora os participantes não reconheceram em nenhuma das duas imagens a que cientista se referia, um maior percentual de alunos (42,31\%) afirmou que a primeira imagem representava um homem da ciência, contra 19,22\% para a segunda imagem. Igualmente, ao responderem justificando o porquê poderia ou não se tratar de um cientista, o número de argumentos, ainda que poucos foi maior para a primeira imagem. Considerando estas respostas, parece ter sido mais fácil justificar o primeiro indivíduo representando um cientista, que o segundo. Conforme o relato dos alunos constatou-se que esses levaram em consideração o ambiente, como por exemplo, "porque na bancada há livros com imagens de corpo humano" e "porque aparecem utensílios de cientista sobre a mesa". Ou seja, os resultados podem estar relacionados ao fato do primeiro indivíduo estar em um ambiente com algumas vidrarias, com coleções de naturalistas e alguns livros.

Já, na segunda imagem de R. Hooke, este se encontrava em um ambiente externo, realizando anotações. Mesmo que de forma sutil, houve pontuações dos alunos para esta imagem, justificando que não poderia se tratar de um cientista porque "era um padre" ou "era um escritor". Ainda foi citado entre os participantes, não se tratar de um cientista na primeira imagem, porque "se tratava de um filósofo" ou "parecia um escritor". Tais colocações mostram as concepções dos estudantes para um cientista que não pode ter outras atribuições além da ciência. Ou seja, o fato de ser um padre, filósofo, escritor ou realizar outra atividade, parece inviabilizar poder ser um cientista, por estar voltado à ideia, de que o cientista deve viver para a ciência, não podendo exercer nenhuma outra atividade.

Além disso, os resultados mostraram um desconhecimento dos alunos no ponto de vista humanista dos próprios homens da ciência. Pode-se lembrar aqui a história de Gregor Mendel e vários outros cientistas naturalistas que contribuíram para a biologia. Um exemplo, são as pesquisas do Pe. Rambo, botânico importante e com contribuições significativas para os estudos de fitofisionomia do país, em especial para o Rio Grande do Sul.

Cachapuz et al. (2005), ao discutirem as visões deformadas de cientistas, apontam para a visão reducionista que os estudantes possuem, com a imagem de um cientista individualista e elitista, de bata branca no seu inacessível laboratório, repleto de estranhos instrumentos e que realiza o trabalho científico, onde experimenta e observa procurando o feliz "descobrimento".

Em relação ao ambiente, Goldschmidt, Jr. Goldschmdit e Loreto (2014), em um estudo sobre as concepções de estudantes em formação docente sobre os cientistas, constataram que para os acadêmicos o ambiente laboratorial, com vidrarias e livros é o mais reconhecido. O estudo de Melo e Rotta (2010) também mostraram que com alunos do ensino fundamental, as perspectivas são as mesmas; ou seja, o cientista ocupa o espaço do laboratório realizando experimentos. A ideia de o "mundo" do cientista ser caracterizado por alguém que estuda muito e quase sempre está nos laboratórios fazendo experiências, é 
discutida também nas pesquisas sobre as concepções de alunos de ensino fundamental (KOSMINSKY e GIORDAN, 2002; REIS e GALVÃO, 2006).

Entendem-se que estas visões ingênuas sobre o cientista podem e devem ser questionadas, a fim de possibilitar uma compreensão maior acerca da natureza do trabalho científico. Os resultados elucidam ainda, que os alunos demonstram não perceberem todas as atribuições de um cientista, inclusive o fato de escreverem muito. Ao observar o fato dos respondentes também justificarem não poder se tratar de um cientista por ser um filósofo, deixa-se de levar em consideração à própria história da ciência. Para entender um pouco mais sobre as funções da filosofia e a maneira como ela opera, Siqueira (2016, p.23-24) afirma que:

A filosofia é um modo de saber que lida com enunciados, sem necessariamente precisar recorrer a experimentos que os comprovem ou refutem. Trata-se, portanto, de uma ciência de natureza teorética e sua finalidade reside em si mesma, tendo como maior pretensão alcançar o conhecimento pelo amor à sabedoria. O motivo que leva o homem a filosofar chama-se espanto ou admiração, provocado com a persistência de uma pergunta diante da manifestação dos fenômenos. Ao perceber que não sabe ou não compreende por qual motivo as coisas são como são, o espanto inicia quando o homem aprende a olhar o mundo de uma maneira que ele não costumava ver. O filósofo é aquele capaz de se surpreender com os fatos e com a ausência de explicações em torno da sua existência e das causas, para depois perguntar "o que é isto?".

Assim, há uma relação estreita entre a ciência e a filosofia, sendo que ambas estão associadas à curiosidade e motivadas pelos questionamentos. Enquanto a ciência procura a resposta de uma maneira mais prática e direta, a filosofia é mais reflexiva e nos faz pensar sobre algo. Xavier (2008) afirma que a colaboração da filosofia para o desenvolvimento do conhecimento científico é mais do que adequada. Na verdade, conhecimento científico e conhecimento filosófico, longe de se excluírem, completam-se.

Basta lembrar de ilustres filósofos e também homens da ciência, como Galilleu Galilei, Aristóteles, Platão e Albert Einsten. Todos trouxeram diversas contribuições à filosofia e à ciência.

Essas ideias compactuam com as de Einstein (1936) apud Cypriano e Teixeira

Segundo ele, a relação recíproca entre a epistemologia e a ciência é de uma espécie notável, em que uma depende da outra. A epistemologia sem contato com a ciência torna-se um esquema vazio, bem como a ciência sem epistemologia é primitiva e confusa. De acordo com Einstein, quando procuramos um fundamento mais sólido para um fenômeno, devemos tentar tornar claro para si próprio de forma crítica os conceitos que utilizamos e as práticas que realizamos (CYPRIANO e TEIXEIRA, 2017, pg. 05).

No que se refere ao fato de não poder ser um cientista por ser um escritor, ao analisar as imagens percebe-se que nas duas imagens, Robert Hooke está com um lápis e um caderno em mãos; ou seja, isto somente foi percebido pelos alunos, pelo fato do cientista estar fora de um ambiente laboratorial. Essa concepção é totalmente errônea, uma vez, que os cientistas também são escritores. Hooke, por exemplo, descrevia e desenhava todas as 
suas observações feitas no microscópio óptico, a qual reuniu no livro intitulado como Micrographia e que trouxe inúmeras contribuições para a história da ciência. Nesse livro, Hooke descreveu a cortiça, a qual, anos mais tarde foi reconhecida como a unidade funcional da vida, a célula (BATISTETI; ARAúJO e CALUZI, 2009).

De forma não significativa, quando os participantes citaram algum nome que identificasse as imagens, obteve-se para as imagens de Robert Hooke, renomes importantes como Isaac Newton, Jean Piaget, Gregor Mendel, Benjamim Franklin, Charles Darwin, Robert Boyle e Sigmund Freud. Observou-se que quando isto ocorreu, os alunos descreveram para os cientistas Isaac Newton e para Gregor Mendel, as contribuições para a física e os estudos de genética sobre as ervilhas, respectivamente. Para Benjamim Franklin foi atribuído os estudos sobre a eletricidade e para Charles Darwin de evolucionista. Isso mostra que o aluno reconheceu o cientista pelas suas contribuições associadas ao nome e não a sua imagem.

De acordo com Martins (2011, p.106) "Robert Hooke (1635-1703) foi um importante filósofo natural que deu contribuições a diversas áreas do conhecimento. Suas contribuições mais conhecidas são no campo da física, mas seus estudos microscópicos sobre seres vivos também foram muito importantes".

Desde criança Hooke já possuía uma grande habilidade manual, tanto para fazer os desenhos de suas observações ao microscópio, quanto para construir instrumentos, como o próprio microscópio que ele utilizava, o qual continha partes removíveis e lentes que poderiam ser trocadas conforme o tamanho do objeto a ser observado. Com o microscópio Hooke realizou diversas observações que incluíam desde objetos inanimados como a ponta de uma agulha, como diversos organismos ou então partes deles (cogumelos, algas, folhas, cabelo, penas, vermes de vinagre etc) (TAVARES e PRESTES, 2012, p.39).

A Tabela 2 apresenta os percentuais analisados para o primeiro questionário, contendo imagens sem o nome do cientista Anton Van Leeuwenhoek.

Sobre as duas imagens de Anton Van Leeuwenhoek, igualmente os respondentes não souberam identificar o cientista, tendo havido um maior número de respostas em branco (92,31\%) na primeira imagem, se comparado com a segunda (73,08\%). Já em relação à questão "É um cientista? ", também não foi significativo este reconhecimento, embora, os valores encontrados superaram os valores para o cientista Robert Hooke, e apresentaram maior significância na segunda ilustração apresentada. Nesta, além de mais alunos nominarem nomes de cientistas, mesmo que erroneamente, o percentual de alunos que consideraram esse um homem da ciência, chegou a 66,67\%. Sobre as justificativas apresentadas pelos alunos, houve repetição dos argumentos construídos para o R. Hooke, sendo citado "se trata de um cientista, pois a imagem apresenta alguns vidros com espécies de animais"; ou seja, levaram em consideração, o ambiente que apareceu na imagem. Já na segunda imagem houve um aluno que respondeu: "é cientista porque criou a lâmpada". Essa resposta mostra igualmente que os elementos que aparecem na imagem, interferiram nas respostas dadas pelos alunos, mais do que a própria imagem do cientista em questão. Nessa imagem, Leeuwenhoek aparece olhando com um microscópio de mão, para a luz. 
Tabela 2. Resultados percentuais encontrados para as imagens do cientista Anton Van Leeuwenhoek, sem a identificação pelo nome, entre alunos concluintes do ensino médio em escolas públicas do interior do estado do Rio Grande do Sul.

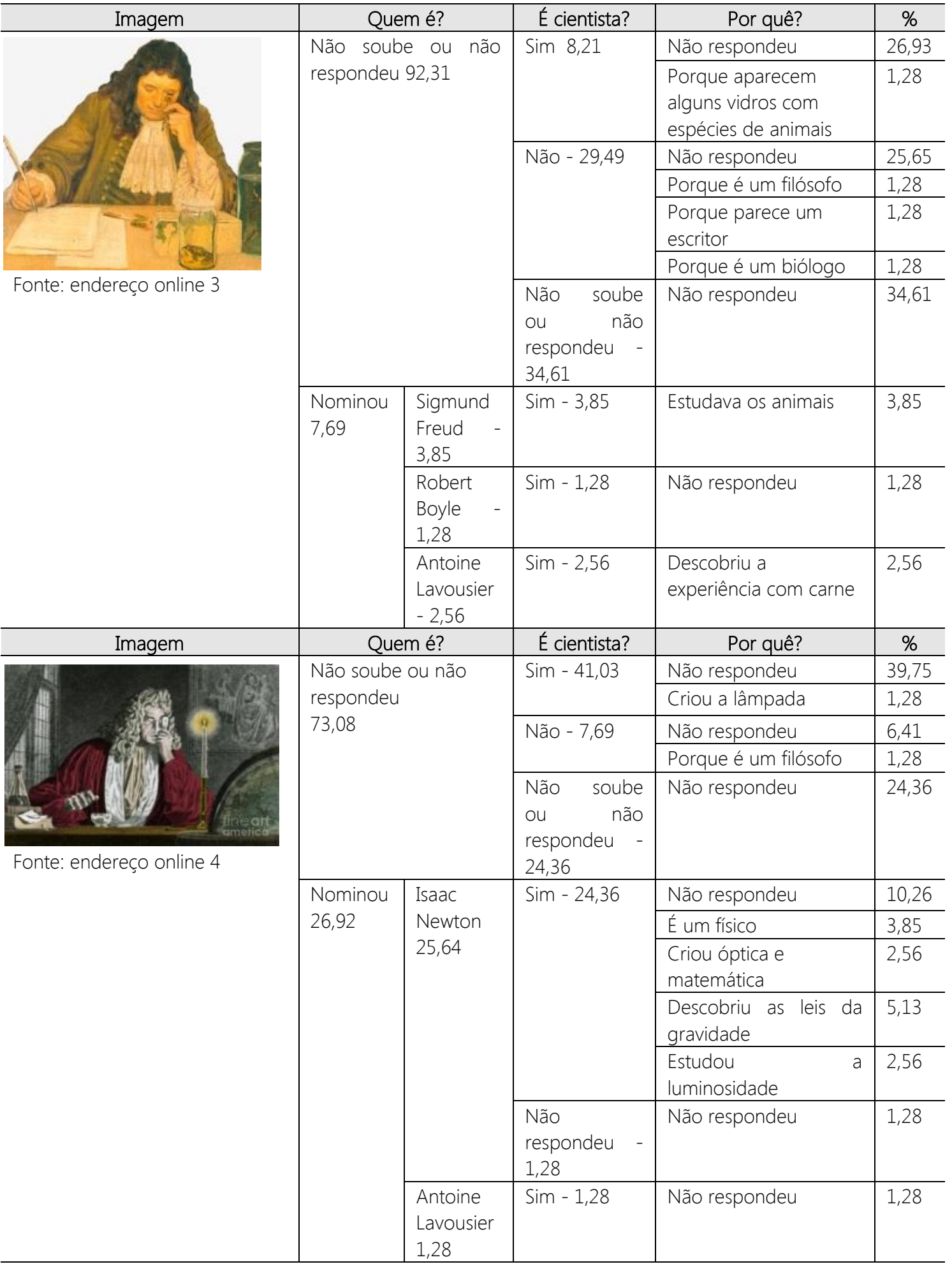

É oportuno destacar que estes dois cientistas, Robert Hooke e Leeuvenhoeck, trouxeram grandes contribuições à ciência, em especial para o aprimoramento dos microscópios óticos e observações neste equipamento. 
Quando questionados sobre o porquê não eram cientistas, a maior porcentagem ficou sem justificativas. No entanto, é importante discutir sobre os poucos argumentos fornecidos pelos alunos para não ser considerado um cientista. Novamente, assim como no cientista anterior, R. Hooke, as respostas estiveram associadas ao fato de se tratar de um filósofo, escritor ou biólogo. É notável a convicção dos alunos sobre uma dicotomia entre filósofo e cientista; ou seja, para eles, só pode ser um ou outro.

Essa imagem já engessada de um cientista, que tanto as mídias quanto muitas vezes a própria sala de aula transmitem, faz com que se acredite que um cientista é um ser único, um gênio louco que inventa coisas fantásticas em um "piscar de olhos"; e mais, não é qualquer pessoa que pode se tornar um cientista.

O cientista virou um mito. E todo mito é perigoso, porque ele induz o comportamento e inibe o pensamento. Este é um dos resultados engraçados (e trágicos) da ciência. Se existe uma classe especializada em pensar de maneira correta (os cientistas), os outros indivíduos são liberados da obrigação de pensar e podem simplesmente fazer o que os cientistas mandam (ALVES, 2005, p. 10).

Sobre parecer ser um escritor, analisando as imagens, percebeu-se que Leeuwenhoek, assim como Hooke, também está com uma caneta em sua mão escrevendo o que estava observando, evidenciando que escrever é uma das atribuições de um cientista e não algo que impede alguém em ser cientista. Muito ao contrário!

Por fim, outra justificativa de um aluno foi: "não é um cientista porque é um biólogo". Essa resposta é um tanto quanto contraditória, pois um biólogo transita facilmente no mundo da ciência, desenvolvendo pesquisas nas mais diversas áreas como botânica, genética, educação (ensino), zoologia, ecologia, entre outras. Esse aluno carece de conhecimento sobre a biologia, e isso pode ser facilmente trabalhado em sala de aula, por qualquer professor, pois no terceiro ano do ensino médio, é necessário ter uma noção mais ampliada das mais distintas áreas de atuação dos profissionais.

Nas imagens que apareceram Leeuwenhoek, os renomes citados foram Sigmund Freud, Robert Boyle e Antoine Lavoisier, em menor percentual. O único nome que teve ampla representação foi Isaac Newton, citado em 25,64\% dos casos. Atribuíram a este o fato de ser um cientista, e o descreveram como físico, que elaborou as leis da gravidade, estudo da luminosidade, matemática e óptica. Todos esses feitos citados mostram que os alunos têm um bom conhecimento sobre Newton, apesar de não corresponder à imagem citada, para a pessoa. Como discutido anteriormente, o fato de observarem olhando com um instrumento para a luz, fez com que os alunos fizessem associações ligadas ao ambiente e aos elementos fornecidos.

Quanto a Sigmund Freud que foi considerado um cientista, houve três respostas, onde os alunos apresentaram uma justificativa errada, dizendo que Freud estudava os animais. Freud foi um importante médico neurologista e psicólogo, importante para a psicanálise. Para Robert Boyle não houve justificativa, o aluno apenas o considerou como um cientista. Já para Antoine Lavoisier houve duas respostas que o consideram cientista e que o mesmo realizou uma experiência com carne, no entanto a experiência da carne foi feita por Francesco Redi. Lavoisier é considerado importante para a química moderna e ficou reconhecido por ter enunciado o princípio da conservação da matéria, apesar de o russo Mikhail Lomonossov, tê-lo feito quatorze anos antes. Ainda realizou estudos sobre a molécula da água, afirmando que a mesma é uma substância composta, formada por 
dois átomos de hidrogênio e um de oxigênio: $\mathrm{H}_{2} \mathrm{O}$. Além disso, realizou estudos sobre o oxigênio.

Assim, ao trabalhar alguma imagem com os estudantes, é fundamental, explorar os elementos contidos nessa, de modo que não façam interpretações imprecisas; pois assim, o aluno irá aprender a interpretar a imagem por si só, sem necessariamente precisar de algum texto complementar, para aprender algo, por exemplo. Segundo Silva et al. (2006, p. 221), "a compreensão das imagens não é imediata, e seu uso no contexto pedagógico da sala de aula exige que o professor saiba como fazê-lo, ou seja, ele pode ajudar o aluno a perceber, entre outros aspectos, os elementos constitutivos da imagem em questão".

Ambos os cientistas Anton Van Leeuwenhoek e Robert Hooke tinham o microscópio como seu favorito hobby e instrumento de trabalho, além de realizar estudos complementares. Anton van Leeuwenhoek (1632-1723) era um simples comerciante de tecidos, quando Hooke começou seus estudos microscópicos. Alguns autores sugerem, sem indicar nenhuma documentação histórica, que foi por causa de seu trabalho por tecidos que ele começou a se interessar por lentes e pela microscopia. Com o passar do tempo Leeuwenhoek começou a se interessar pela microscopia e pela ciência, onde por meio de uma carta que ele próprio escreveu a Royal Society em 1685, ele forneceu informações sobre o início de sua carreira científica. Leeuwenhoek tinha muitos amigos cultos pelos quais mantinha contato e os ajudavam (MARTINS, 2011, p.132-133).

Segundo Brito (2008, p.40) "com o seu microscópio simples, Leeuwenhoeck foi protagonista de importantes descobertas no mundo microscópico, como os glóbulos vermelhos, os espermatozoides, algumas espécies de protozoários e bactérias, que designou por "animáculos" (pequenos animais)".

As Tabelas 3 e 4 elucidam os resultados quando além da imagem do cientista, foi fornecido o nome do mesmo. Percebe-se, que mesmo quando isso aconteceu, os alunos praticamente não os identificaram, o que sinaliza que a abordagem histórica quase não se faz presente no ensino de ciências.

É importante ressaltar que a história da ciência deve ser trabalhada a fim de tornar o ensino mais interessante e realista. Por meio da história o aluno consegue desmistificar certos fatos que ocorreram ao longo do tempo a respeito da ciência e dos cientistas. Para isso, é importante que o professor busque conhecimento além do imposto pelos livros didáticos e pela mídia, pois esses muitas vezes nos passam uma visão totalmente fragmentada e ingênua da real natureza da ciência.

Pasquetti (2011) em um estudo feito para identificar a abordagem histórica nos livros didáticos de biologia, analisou dois livros em volumes únicos e duas coleções de três livros, onde identificou uma abordagem reducionista sobre os cientistas Hooke e Leeuwenhoek, sendo associada a eles, a descoberta da microscopia óptica. Nestes livros inclusive foram apresentadas imagens apenas do Leeuwenhoek, e foi atribuído a Hooke, apenas as observações da cortiça.

Infelizmente o uso de imagens ainda é muito restrito em sala de aula, geralmente os alunos acabam tendo acesso apenas às imagens presentes nos livros didáticos, os quais de uma maneira geral, prezam por imagens explicativas de um fenômeno ou estrutura, e então, os cientistas são na maioria das vezes, somente citados pelo nome, o que pode ser um dos fatores desse desconhecimento pela imagem. 
Tabela 3. Resultados percentuais encontrados para a imagem do cientista Robert Hooke com a identificação pelo nome, entre alunos entre alunos concluintes do ensino médio.

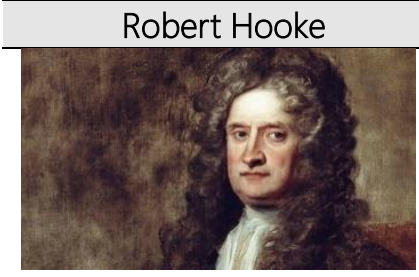

Fonte: endereço online 5

\begin{tabular}{|c|c|c|c|}
\hline & & Abs. & $\%$ \\
\hline \multicolumn{2}{|c|}{ Reconheci pela imagem } & 8 & 10,26 \\
\hline \multicolumn{2}{|c|}{ Não reconheci pela imagem } & 58 & 74,36 \\
\hline \multicolumn{2}{|l|}{ Deixou em branco } & 12 & 15,38 \\
\hline \multicolumn{2}{|l|}{ Já ouvi falar o nome } & 28 & 35,90 \\
\hline \multicolumn{2}{|c|}{ Nunca ouvi falar o nome } & 45 & 57,69 \\
\hline \multicolumn{2}{|l|}{ Deixou em branco } & 5 & 6,41 \\
\hline \multicolumn{2}{|l|}{ Sei o que fez } & 9 & 11,54 \\
\hline \multicolumn{2}{|l|}{ Não sei o que fez } & 59 & 75,64 \\
\hline \multicolumn{2}{|l|}{ Deixou em branco } & 10 & 12,82 \\
\hline \multirow[t]{5}{*}{ O que sabe dele? } & Não soube ou não respondeu & 69 & 88,46 \\
\hline & Era físico & 4 & 5,13 \\
\hline & Inventor do microscópio & 3 & 3,85 \\
\hline & Criou o telescópio & 1 & 1,28 \\
\hline & Roubou a ideia de Newton & 1 & 1,28 \\
\hline
\end{tabular}

Tabela 4. Resultados percentuais encontrados para a imagem do cientista Anton Van Leeuwenhoek, com a identificação pelo nome, entre alunos concluintes do ensino médio.

\begin{tabular}{|c|c|c|c|}
\hline Anton Van Leeuwenhoek & Questões & Abs. & $\%$ \\
\hline & Reconheci pela imagem & 1 & 1,28 \\
\hline & Não reconheci pela imagem & 64 & 82,05 \\
\hline & Deixou em branco & 13 & 16,67 \\
\hline & Já ouvi falar o nome & 12 & 15,38 \\
\hline & Nunca ouvi falar o nome & 60 & 76,92 \\
\hline & Deixou em branco & 6 & 7,69 \\
\hline \multirow{4}{*}{ Fonte: endereço online 6} & Sei o que fez & 3 & 3,85 \\
\hline & Não sei o que fez & 64 & 82,05 \\
\hline & Deixou em branco & 11 & 14,10 \\
\hline & Não soube ou não respondeu & 78 & 100,00 \\
\hline
\end{tabular}

É oportuno destacar que os dois cientistas, Robert Hooke e Anton Leeuvenhoeck, trouxeram grandes contribuições à ciência, em especial para o aprimoramento dos microscópios óticos e observações neste equipamento. Esses dois cientistas abriram horizontes para a ciência, porém, não pode ser atribuída a eles a descoberta do microscópio, pois já haviam outros cientistas, fabricantes de óculos, que estavam estudando.

Segundo Barbosa e Corte-Real (2010) acredita-se que o primeiro microscópio tenha sido inventado em 1592, por Jeiniere da Cruz e seu pai, Zacharias Jansen, dois holandeses fabricantes de óculos. Tudo indica, porém, que o primeiro a fazer observações microscópicas de materiais biológicos foi Antonie van Leeuwenhoek (1632-1723). O microscópio simples com apenas uma lente, construído por Leeuwenhoek, foi aprimorado por Robert Hooke em 1665, ganhando mais uma lente. 
Na Tabela 3 ainda pode-se analisar que dos 11,54\% alunos que responderam saber o que Hooke fez, 1,28\% se referiram também a ter criado o telescópio. Brito (2008) afirma que o telescópio de reflexão que já tinha sido projetado por James Gregory, mas nunca colocado em prática, tendo sido Hooke que o fez.

Uma pequena porcentagem afirmou também que Hooke "roubou a ideia de Newton". Brito (2008) sinaliza que Newton e muitos outros cientistas, como Robert Hooke protagonizaram a revolução científica no séc. XVII, e junto com essa relação existia muita divergência de ideias e até certa desavença entre eles. Porém, não se achou nenhum registro afirmando que Hooke se apropriou indevidamente de alguma ideia de Newton.

É oportuno destacar que os dois cientistas, Hooke e Leeuvenhoeck, trouxeram grandes contribuições à ciência, em especial para o aprimoramento dos microscópios óticos e observações neste equipamento. Ao observar nos resultados que tanto apresentando as imagens dos cientistas, quanto fornecendo os nomes, os alunos praticamente não os identificaram, percebe-se que a abordagem histórica quase não se faz presente no ensino de ciências. Apenas no caso do Hooke, alguns participantes associaram ao microscópio e, quando o fizeram, o retrataram como inventor, o que não é verdade.

A Tabela 5 apresenta os percentuais analisados para o primeiro questionário, contendo imagens sem o nome do cientista Carl Nilsson Linnaeus.

Tabela 5. Resultados encontrados para as imagens do cientista Carl Nilsson Linnaeus (Carlos Lineu), sem a identificação pelo nome, entre alunos concluintes do ensino médio.

\begin{tabular}{|c|c|c|c|c|c|}
\hline Imagem & & \multicolumn{2}{|l|}{ É cientista? } & Por quê? & $\%$ \\
\hline & \multirow{4}{*}{$\begin{array}{l}\text { Não } \\
\text { soube ou } \\
\text { não } \\
\text { respondeu } \\
100,0\end{array}$} & \multicolumn{2}{|l|}{$\operatorname{Sim}-8,97$} & Não respondeu & 8,97 \\
\hline & & \multirow{2}{*}{\multicolumn{2}{|c|}{ Não - 43,59 }} & Não respondeu & 42,31 \\
\hline & & & & $\begin{array}{l}\text { Não há nada que } \\
\text { demonstre que ele } \\
\text { seja um cientista }\end{array}$ & 1,28 \\
\hline $\begin{array}{l}\text { a alamy stock photo } \\
\text { Fonte: endereço online } 7\end{array}$ & & \multicolumn{2}{|c|}{$\begin{array}{l}\text { Não soube ou não } \\
\text { respondeu - } 47,44\end{array}$} & Não respondeu & 47,44 \\
\hline & Quem é? & \multicolumn{2}{|c|}{ É cientista? } & Por quê? & $\%$ \\
\hline & & \multicolumn{2}{|l|}{ Sim - 7,69 } & Não respondeu & 7,69 \\
\hline & soube ou & \multicolumn{2}{|l|}{ Não - 41,03 } & Não respondeu & 41,03 \\
\hline & $\begin{array}{l}\text { não } \\
\text { respondeu } \\
87,18\end{array}$ & \multicolumn{2}{|c|}{$\begin{array}{l}\text { Não soube ou não } \\
\text { respondeu - } 38,46\end{array}$} & Não respondeu & 38,46 \\
\hline & Nominou & $\begin{array}{l}\text { Isaac Newton } \\
7,69\end{array}$ & $\begin{array}{l}\operatorname{sim} \\
7,69\end{array}$ & Não respondeu & 7,69 \\
\hline \multirow[t]{2}{*}{ Fonte: endereço online 8} & \multirow[t]{2}{*}{12,82} & $\begin{array}{l}\text { Sigmund Freud } \\
1,28\end{array}$ & $\begin{array}{l}\text { Sim } \\
1,28\end{array}$ & Não respondeu & 1,28 \\
\hline & & $\begin{array}{l}\text { Lev } \\
\text { Semyonovich } \\
\text { Vygotsky } \\
3.85\end{array}$ & $\begin{array}{l}\text { Sim } \\
3,85\end{array}$ & É um neurologista & 3,85 \\
\hline
\end{tabular}

Ainda, um terceiro cientista não foi reconhecido pelas imagens, se refere ao botânico sueco Carolus Linnaeus, ou Lineu. Na primeira imagem, o cientista aparece tirando um "cochilo" em um ambiente no qual realizava seus estudos, e onde encontramos alguns vestígios de plantas, um chapéu, uma mesa, e provavelmente seu companheiro de saídas 
de campo, seu cachorro, que por sinal também está descansando, quiçá, após um dia exaustivo de pesquisas a campo.

Mesmo para quem não reconhece Lineu fisicamente, a imagem fornece informações sobre um cientista naturalista, por meio dos objetos presentes no ambiente, sendo que as plantas são a maior identidade de um botânico. No entanto, desta vez, ao contrário do que aconteceu com os outros dois cientistas, os elementos presentes no ambiente parecem não ter influenciado nas respostas. Talvez o fato, do comportamento, no caso, descanso, interferiu mais. O mesmo aconteceu na segunda imagem, em que Lineu aparece em uma "conferência" apresentando dados ou discutindo provavelmente a respeito de ciência com outras pessoas. Esta imagem também não foi identificada pelos alunos como uma possibilidade de se tratar de um cientista.

Os resultados mostram que apenas $29,48 \%$ dos alunos responderam se tratar de um cientista nas imagens, sendo que ao consideramos a primeira imagem, este número foi menos significativo que na segunda imagem.

Os resultados indicam que há ainda uma concepção ingênua e "engessada" do cientista, carecendo maiores informações e discussões na sala de aula, sobre um cientista naturalista e do campo.

[...] o desconhecimento sobre como pensam e agem os cientistas impede a aproximação dos alunos à cultura científica. Consequência imediata deste impedimento é a tentativa de transferência acrítica dos valores prezados pela cultura científica para os estudantes, por exemplo, conceitos, procedimentos, regras para validação de modelos, sem que Ihes seja dada a oportunidade de vivenciar, com base na necessária transposição já mencionada, formas de agir e pensar típicas das ciências (KOSMINSKY e GIORDAN, 2002, p.15).

A maneira como o ensino é proposto aos alunos, impede com que os mesmos reflitam e criem suas próprias opiniões. Geralmente, o conteúdo é passado como uma verdade imutável, e isso também contribui para essa visão de que um cientista é um gênio, e acaba deixando de lado a verdadeira história da ciência, na qual esses cientistas eram pessoas normais que passaram por dificuldades econômicas, políticas e sociais para então alcançar seus objetivos, além disso, eles podem possuir uma vida social, não vivendo exclusivamente para a ciência, compartilhando momentos de descontração, descanso e lazer. Freitas et al. (2016), em suas pesquisas, descreveram que a maioria dos estudantes não percebem os cientistas como "pessoas comuns", não sendo visto para além de sua atividade profissional. Tal concepção é fundamental, uma vez que atribui uma visão humanizada à atividade científica, uma vez que o cientista é visto como um ser humano que desenvolve atividades (descansam, passeiam, dormem, entre outros), para além do seu trabalho. Essa concepção se distância de imagens construídas na mídia sobre o cientista (SIQUEIRA, 2002; MESQUITA e SOARES, 2008).

A respeito do não reconhecimento da atividade coletiva representada na segunda figura do cientista Lineu, Freitas et al. (2016) mostram em suas pesquisas que as atividades coletivas são praticamente ignoradas pelos estudantes e revelam uma concepção ingênua sobre indivíduos como sujeitos que trabalham solitários, isolados da sociedade, ausentes de colaborações em suas pesquisas.

Cachapuz et al. (2011) e Fernandez et al. (2002) discutem que esta visão individualista do trabalho do cientista, no qual os conhecimentos científicos aparecem como obras de 
gênios isolados pode construir distorções no que se refere à concepção da atividade científica, bem como a maneira em que a Ciência é produzida, disseminando uma concepção de Ciência elitista e destinada a uma pequena parcela da sociedade, os gênios.

Entre os renomes citados para as imagens de Lineu, obtivemos Isaac Newton, Sigmund Freud e Lev Semyonovich Vygotsky. Apenas Vygotsky foi justificado se tratar de um cientista, por ser um neurologista, o que é verdadeiro, além de ter realizado estudos na área da psicologia.

Esses resultados mostram que os alunos possuem razoável conhecimento sobre algumas das contribuições desses cientistas, mesmo não tendo reconhecido o cientista pelas imagens, o que não é uma tarefa tão fácil para quem não tem muito acesso a materiais que possam fornecer, pois as mesmas geralmente não têm sido usadas no ensino.

Vale ainda salientar aqui um pouco sobre a história de vida de Lineu que desde jovem já apresentava uma grande afinidade por plantas. Lineu ficou muito conhecido por seus estudos botânicos ligados a classificação das plantas, que sob o ponto de vista mais prático, segundo Prestes, Oliveira e Jensen (2009, p.105):

A diversidade biológica impõe algum tipo de organização para que se possa conhecer e fazer uso das diferentes espécies de animais e vegetais, bem como de microrganismos. É uma necessidade sentida em diferentes culturas e épocas a de agrupar diferentes organismos e referir-se a eles com nomes como "comestíveis" ou "venenosos", "animais" ou "vegetais", "aves" ou "peixes" etc.

Com isso, constata-se que os estudos de Lineu foram extremamente importantes, pois forneceram informações necessárias a respeito dos diferentes organismos vivos.

Tabela 6. Resultados encontrados para as imagens do cientista Carl Nilsson Linnaeus (Carlos Lineu), com a identificação pelo nome, entre alunos concluintes do ensino médio em escolas públicas do interior do estado do Rio Grande do Sul.

\begin{tabular}{|c|c|c|c|c|}
\hline Robert Hooke & \multicolumn{2}{|r|}{ Questões } & Abs. & $\%$ \\
\hline & \multicolumn{2}{|c|}{ Reconheci pela imagem } & 4 & 5,13 \\
\hline & \multicolumn{2}{|c|}{ Não reconheci pela imagem } & 60 & 76,92 \\
\hline & \multicolumn{2}{|l|}{ Deixou em branco } & 14 & 17,95 \\
\hline & \multicolumn{2}{|l|}{ Já ouvi falar o nome } & 26 & 33,33 \\
\hline & \multicolumn{2}{|c|}{ Nunca ouvi falar o nome } & 51 & 65,38 \\
\hline & \multicolumn{2}{|l|}{ Deixou em branco } & 1 & 1,28 \\
\hline & \multicolumn{2}{|l|}{ Sei o que fez } & 13 & 16,67 \\
\hline & \multicolumn{2}{|l|}{ Não sei o que fez } & 54 & 69,23 \\
\hline Fonte: endereço online 9 & \multicolumn{2}{|l|}{ Deixou em branco } & 11 & 14,10 \\
\hline & \multirow[t]{6}{*}{ O que sabe dele? } & Não soube ou não respondeu & 65 & 83,33 \\
\hline & & Taxonomia & 7 & 8,97 \\
\hline & & Ajudou na biologia & 2 & 2,56 \\
\hline & & $\begin{array}{l}\text { Elaborou a teoria da evolução } \\
\text { das espécies }\end{array}$ & 2 & 2,56 \\
\hline & & É um historiador & 1 & 1,28 \\
\hline & & Foi um botânico & 1 & 1,28 \\
\hline
\end{tabular}


Quando apresentado o nome do cientista associado a sua imagem, pode-se verificar que igualmente o cientista não foi reconhecido significativamente pelos participantes. Os resultados encontram-se na Tabela 6.

Em relação a Lineu, mesmo sendo nomeado, 65,38\% afirmaram nunca terem ouvido o nome e 69,23\% responderam não conhecer seus estudos e contribuições. Apenas 10,25\% associaram aos estudos de botânica e taxonomia. Segundo Buckeridge (2008) Carlos Lineu se tornou um dos maiores botânicos da história ao estabelecer e aperfeiçoar o princípio básico usado para classificar os seres vivos.

Ao que se refere a "Elaborou a teoria da evolução das espécies" que 2,56\% dos alunos mencionaram, identifica-se que houve uma confusão ao relacionar seu nome diretamente com esta teoria. Deve-se ressaltar que o trabalho de Lineu foi de grande importância a gradual elaboração da Teoria desenvolvida por Charles Darwin, ao mesmo tempo, Darwin contribuiu com o desenvolvimento da classificação dos seres vivos.

\section{Considerações finais}

Os resultados revelam que o uso de imagens ainda é restrito em sala de aula, e quando acontece geralmente os alunos acabam tendo acesso apenas às imagens presentes nos livros didáticos, os quais prezam mais por imagens explicativas, de um fenômeno ou estrutura, e então, os cientistas são na maioria das vezes, somente citados pelo nome, o que pode ser um dos fatores do desconhecimento do cientista pela imagem.

Embora os alunos, quando citado o nome do cientista, citaram algumas de suas contribuições, apresentar de forma adequada e ampliada a História da Ciência pode contribuir como um dispositivo didático útil, tornando o ensino da ciência a nível médio mais interessante, além de facilitar a aprendizagem. Mostrar através de episódios históricos o processo gradativo e lento de construção do conhecimento permite aos alunos uma visão ampliada sobre o processo de construção da ciência, e que esta não é imutável e que depende de diversas pessoas, motivadas por inquietações e curiosidades, que procuram estudar e encontrar respostas.

\section{Referências}

ALVES, R. Filosofia da ciência. Introdução ao jogo e a suas regras. São Paulo: Loyola, $10^{\circ}$ edição, 2005.

BARBOSA, H. S.; CORTE-REAL, S. Biologia celular e ultraestrutura. In: MOLINARO, E. M. Conceitos e métodos para a formação de profissionais em laboratórios de saúde. vol. 2. Organização MOLINARO, E. M.; CAPUTO, L. F. G. e AMENDOEIRA, M. R. R. Rio de Janeiro: EPSJV; IOC, 2010.

BATISTETI; C. B.; ARAÚJO, E. S. N. e CALUZI, J. J. As estruturas celulares: o estudo histórico do núcleo e sua contribuição para o ensino de biologia. In: Filosofia e História da Biologia. Anais... Campinas, SP: ABFHiB, São Paulo: FAPESP, Rio de Janeiro: Booklink, vol. 4, jan./dez. 2009.

BRITO, A. A. Quem tramou Robert Hooke. Ciência \& Tecnologia dos Materiais, vol. 20, n. $3 / 4,2008$. 
BUCKERIDGE, Marcos. Deus fez, Lineu organizou. Mar. 2008.

CACHAPUZ A. et al. A necessária renovação do ensino de ciências. São Paulo: Cortez, 2005

CACHAPUZ, A.; et al (Orgs.). A necessária renovação do ensino de ciências. São Paulo: Cortez, 2 Ed., 2011.

CYPRIANO, R. J. e TEIXEIRA, R. D. B. L. Etnociência da ciência: a busca por simetria na pesquisa científica. Revista Inter. Interdisc. INTERthesis, Florianópolis, v.14, n.3, p. 01-13 Set.Dez. 2017

FERNANDEZ, I.; et al. Visiones deformadas de la ciencia transmitidas por la enseñanza. enseñanza de las ciencias. Historia y epistemología de las ciencias. v. 20, n. 3, p. 477-488, 2002.

FREITAS, B. S. P. et al. Representações sobre cientistas entre estudantes em formação docente em biologia e química. Revista Metáfora Educacional. Bahia (Brasil), n. 21, jul. - dez. 2016, p. 24-51.

GOLDSCHMIDT, A. I.; GOLDSCHMIDT JUNIOR, J. L.; LORETO, E. L. S. Concepções referentes à ciência e aos cientistas entre alunos de anos iniciais e alunos em formação docente.

Contexto \& Educação. v.92, p.132 - 164, 2014.

HÖTTECKE, D.; SILVA, C. C. Why implementing history and philosophy in school science education is a challenge: an analysis of obstacles. Science \& Education, n. 20, p. 293-316, 2011.

KOMINSKY, L.; GIORDAN, M. Visões sobre Ciências e sobre Cientista entre. Estudantes do Ensino Médio. Química Nova na Escola, v. 15, p. 11-18, 2002.

MARTINS, L. A-C. P. A história da Ciência e o ensino da Biologia. Ciência e Ensino, n. 7, 1998, p. 18-21.

MARTINS, A. F. História e filosofia da ciência no ensino: há muitas pedras nesse caminho Cad. Bras. Ens. Fís., v. 24, n. 1: p. 112-131, abr. 2007

MARTINS, R. A. Robert Hooke e a pesquisa microscópica dos seres vivos. Filosofia e História da Biologia, v. 6, n. 1, p. 105-142, 2011.

MATTHEWS, M. R. História, filosofia e ensino de ciências: a tendência atual de reaproximação. Caderno Catarinense de Ensino de Física, v. 12, n. 3, p. 164-214, Florianópolis, 1995.

MELO, J. R.; ROTTA, J. C. G. Concepção de ciência e cientista entre estudantes do ensino fundamental. Anais... In: XV Encontro Nacional de Ensino de Química, Brasília-DF, 2010.

MELZER, M. e AIRES, J. A. A História do desenvolvimento da teoria atômica: um percurso de Dalton a Bohr. Amazônia, Revista de Educação em Ciências e Matemática, v.11 (22) Jan-Jun 2015. p.62-77.

MESQUITA, N. A. S.; SOARES, M. H. F. B. Visões de ciência em desenhos animados: uma alternativa para o debate sobre a construção do conhecimento científico em sala de aula.

Ciência e Educação, v. 14, n. 3, p. 417-429, 2008.

PASQUETTI, M. V. A História da ciência nos livros didáticos de Biologia. Porto Alegre:

Universidade Federal do Rio Grande do Sul, 2011. 113p 
PRESTES, M.E; OLIVEIRA, P; JENSEN, G.M. As origens da classificação de plantas de Carl von Linné no ensino de biologia. Filosofia e História da Biologia, v. 4, p. 101-137, 2009.

REIS, P.; GALVÃO, C. O diagnóstico de concepções sobre os cientistas através da análise e discussão de histórias de ficção científica redigidas pelos alunos. Revista Electrónica de Enseñanza de las Ciencias, v.. 5, n. 2, 2006.

SILVA, H. C. da et al. Cautela ao usar imagens em aulas de ciências. Ciência \& Educação (Bauru), vol. 12, núm. 2, agosto, 2006, pp. 219-233

SIQUEIRA, A. C. A. O significado de filosofia na metafísica de Aristóteles e sua influência no pensamento de Heidegger. Kínesis - Revista de Estudos dos Pós-Graduandos em Filosofia, v. 8, n. 18,2016, p.18-30

SIQUEIRA, D. C. O. Ciência e poder no universo simbólico do desenho animado. In: MASSARAN, L.; CASTRO. I. M.; BRITO, F. (Orgs). Ciência e público: caminhos da divulgação científica no Brasil. Rio de Janeiro: Casa da Ciência - Centro Cultural de Ciência e Tecnologia da Universidade Federal do Rio de Janeiro. Fórum de Ciência e Cultura, 2002. 232 p. (Série Terra Incógnita, v. 1).

TAVARES, T. F; PRESTES, M. E. Pseudo-história e ensino de ciências: o caso Robert Hooke (1635-1703). Revista da Biologia, v.9, n. 2, 2012, p.35-42.

XAVIER, B. R. As categorias de Aristóteles e o conhecimento científico. Pensar, Fortaleza, v. 13, n. 1, p. 57-64, jan./jun. 2008.

ZANON, D. A. V.; MACHADO, A. T. A visão do cotidiano de um cientista retratada por estudantes iniciantes de licenciatura em química. Ciências \& Cognição, v.18, n. 1, 2013.

\section{Referências online das imagens}

Endereço online 1: www.chicagonow.com/quark-in-the-road/2013/07/robert-hooke-

multidimentional-scientist-and-polymath/

Endereço online 2:

www.en.wikipedia.org/wiki/Robert_Hooke\#/media/File:Memorial_portrait_of_Robert_Hooke_at_Alum_ Bay,_IoW_for_Carisbrooke_Museum.JPG

Endereço online 3: www.br.pinterest.com/pin/340092209346669947/

Endereço online 4: www.quibiolegal.blogspot.com/2014/04/introducao-citologia.html

Endereço online 5: www.jeanplemos.wordpress.com/category/biologia-celular/

Endereço online 6: www.sites.hps.cam.ac.uk/whipple/explore/microscopes/adutchpioneer

Endereço online 7: www.alamy.com/stock-photo-young-linnaeus-tired-out-after-a-day-in-the-fieldscarl-linnaeus-may-103996931.html

Endereço online 8: www.naturlink.pt/article.aspx?cid=13475\&menuid=17\&bl=1\&viewall=true

Endereço online 9: www.naturlink.pt/article.aspx?cid=13475\&menuid=17\&bl=1\&viewall=true 